\title{
SURGERY IN GENERAL
}

\section{Alcohol skin preparation causes surgical fires}

\author{
B Rocos, LJ Donaldson
}

National Patient Safety Agency, London, UK

ABSTRACT

INTRODUCTION Surgical fires are a rare but serious preventable safety risk in modern hospitals. Data from the US show that up to 650 surgical fires occur each year, with up to $5 \%$ causing death or serious harm. This study used the National Reporting and Learning Service (NRLS) database at the National Patient Safety Agency to explore whether spirit-based surgical skin preparation fluid contributes to the cause of surgical fires.

METHODS The NRLS database was interrogated for all incidents of surgical fires reported between 1 March 2004 and 1 March 2011. Each report was scrutinised manually to discover the cause of the fire.

RESULTS Thirteen surgical fires were reported during the study period. Of these, 11 were found to be directly related to spiritbased surgical skin preparation or preparation soaked swabs and drapes.

CONCLUSIONS Despite manufacturer's instructions and warnings, surgical fires continue to occur. Guidance published in the UK and US states that spirit-based skin preparation solutions should continue to be used but sets out some precautions. It may be that fire risk should be included in pre-surgical World Health Organization checklists or in the surgical training curriculum. Surgical staff should be aware of the risk that spirit-based skin preparation fluids pose and should take action to minimise the chance of fire occurring.

\section{KEYWORDS}

Fires - Operating rooms - Surgery - Safety

Accepted 13 October 2011

CORRESPONDENCE TO

Brett Rocos, Clinical Advisor, National Patient Safety Agency, 4-8 Maple Street, London W1T 5HD, UK

T: +44 (0)20 7927 9218; E: brettrocos@gmail.com

Fires in the operating room are one of the most serious risks that can affect the safety of patients in a modern hospital. Although not common, an estimated 550-650 such fires occur annually in the US, with $5 \%$ causing death or serious harm. ${ }^{1}$ They are all potentially preventable.

It is usually assumed that such fires are associated with flammable anaesthetic gases and while this is so, alcoholbased skin preparation fluids are also implicated ${ }^{2}$ although this has been insufficiently documented. ${ }^{3,4}$ Awareness of this potential fire risk is low among surgeons, scrub nurses and other operating room staff. Several case studies detail individual cases where patients have been killed by fires attributed to alcohol-based skin preparation fluids..$^{4,5}$

We used a national database of five million patient safety incidents to explore the role of alcohol-based skin preparation fluids in the causation of surgical fires.

\section{Methods}

The National Patient Safety Agency was established in 2001 to develop programmes of patient safety within the National Health Service (NHS) in England and Wales. One of its key functions was to establish and maintain a database of patient safety incidents that could be used to: analyse the main sources of harm and their causes; identify action that could reduce risk; and monitor trends, patterns and severity of un- safe care. All providers of NHS care are strongly encouraged to report patient safety incidents. These are defined as 'any unintended or unexpected incidents which could have, or did, lead to harm for one or more patients receiving NHSfunded healthcare'. ${ }^{6}$

The electronic reporting form is semi-structured. Many of the fields are categorised, covering administrative data, patient demographics, devices and medicines involved, times, dates and type of incident. A free text field allows the reporter to describe the incident. Since reporting began in 2003, around five million incident reports have been accumulated.

Incidents are classified by the reporter into five categories: no harm, low harm, moderate harm, severe harm and death. Those incidents reported as causing severe harm or death are clinically reviewed for the appropriate assignment of the degree of harm before being further investigated.

In this study, the database was interrogated using key terms to identify incidents involving fires in the operating theatre.

\section{Results}

The search yielded 13 reports of fires during a surgical procedure. Of these, 11 were attributed to the presence of flammable skin preparation fluid and two to the misuse of equipment causing ignition. None of the patients concerned were 


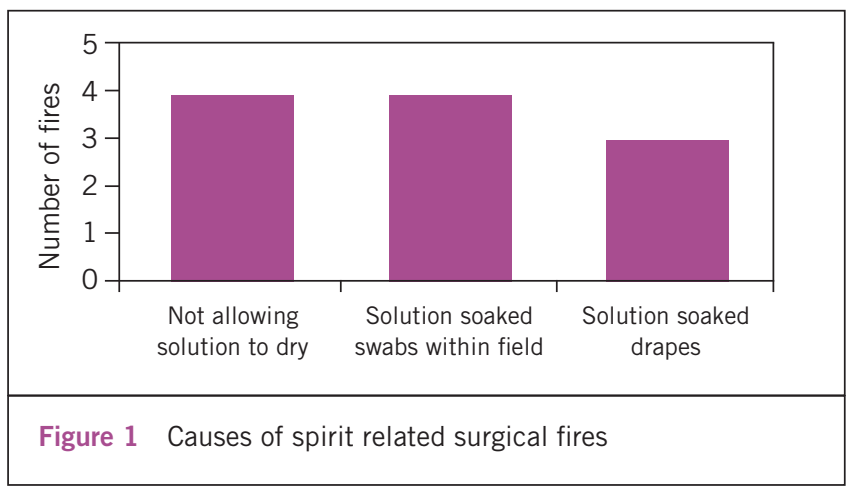

killed but one suffered severe harm, two moderate harm and the remaining ten were judged to have suffered no or a low level of harm. In eight cases, chlorhexidine solution was used, in one case povidone-iodine and in two cases the causative solution was not detailed.

The causes of the fires are shown in Figure 1. The majority of fires were caused either by the skin preparation solution not being given enough time to dry or because swabs soaked with the fluid were left in the operating field within an unsafe distance of the ignition source. In one case, a soaked swab that had been used to mop up excess chlorhexidine made the fire worse. In two cases, the antiseptic soaked swab was not properly disposed of before electrosurgical instruments were used. In the incident involving ignited drapes, the alcoholic solution saturated fabric of the drapes was set alight. In one case, the drape was named simply as a 'paper drape' in the incident report while in the second case no comment was made on the fabric.

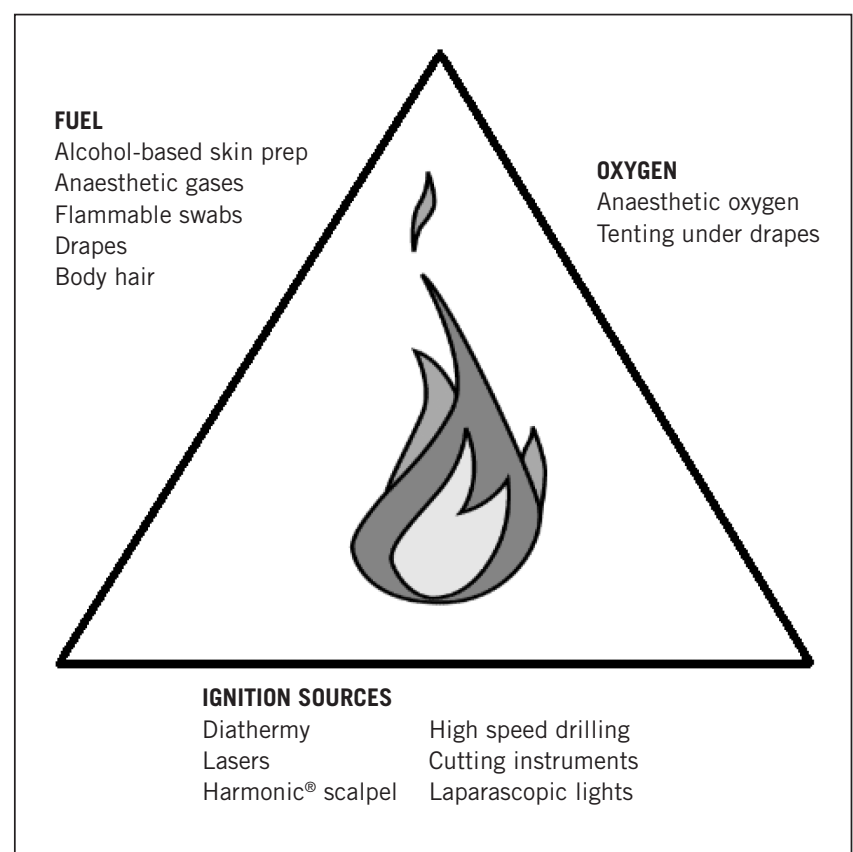

Figure 2 The fire triangle showing sources of fuel, ignition and oxygen in the operating room

\section{Discussion}

Surgical fires are a recognised, documented hazard in modern operating rooms yet awareness of surgical fire risk is low. ${ }^{7}$ The whole surgical team has a role to play in minimising this risk as all three sides of the fire triangle are represented within the theatre: oxygen rich environments being generated by anaesthetic gas use and tenting within the surgical drapes; fuel from skin preparation fluids, flammable swabs, drapes and body hair; and ignition sources from diathermy, lasers or high speed drilling and cutting instruments (Fig 2).

In our study, reported surgical fires were most commonly attributed to the presence of a flammable skin preparation fluid. Alongside case studies in the literature, this provides evidence that some formal assessment and mitigation of fire risk in operating rooms is necessary.

In the UK, spirit-based antiseptic fire risk is recognised by standard setting and regulatory bodies. Guidelines published in 2008 recommend that the surgeon should ensure the evaporation of alcohol substances before surgery begins $^{8}$ and in 2000 a regulatory warning was issued stating that spirit-based skin preparation fluid should be not be allowed to pool and should be dry or dried before electrosurgery commences. ${ }^{9}$

In the US, the Association of periOperative Registered Nurses and the ECRI Institute (formerly the Emergency Care Research Institute) have issued guidelines to reduce the fire risk in operating rooms. ${ }^{1,10}$ These guidelines detail straightforward interventions, including a time-out to ensure drying of alcohol-based skin preparation fluid and the non-storage of such compounds in the operating area. As yet there are no data to show whether these guidelines have reduced the frequency of fires.

There has been more action aimed at preventing surgical fires in the US, possibly because of the more litigious culture. In a further effort to reduce the incidence of pooling and an excess application of alcohol-based skin preparation fluid, the Center for Medicaid has published advice stating that alcohol-based skin preparation solutions should be applied using a purpose built applicator that allows the dissipation of vapour, minimises pooling and excess application of solution, and controls the flow of solution. ${ }^{11}$

The manufacturers of spirit-based surgical preparation solutions provide clear advice regarding fire precautions when using these products via their product instructions and the Summary of Product Characteristics (SPC). For chlorhexidine, the manufacturer recommends that the product be allowed 'to dry completely before starting any medical procedure'. The instructions go on to say 'do not use with electrocautery procedures until dry'. ${ }^{12}$

The SPC for povidone-iodine states that it is an alcoholbased solution but it does not advise on fire precautions. ${ }^{13}$ Manufacturers' instructions are very clear when it comes to absorbent materials: 'Remove any soaked materials, drapes or gowns before proceeding. ${ }^{14}$ However, there are no standards for flame retardancy or absorbency for surgical drapes, either disposable or reusable cotton types. Similarly, there are no fire regulations for surgical swabs despite their liability to extensively soak up any fluid. 
When it comes to the disposal of surgical spirits, the SPC for chlorhexidine states: 'The solution is flammable. Do not use while smoking, or near any naked flames or strong heat source. ${ }^{15}$ It is not clear why this is emphasised only for disposal and not for use.

The risk of surgical fires due to spirit-based skin preparation fluid should be actively reduced. Simply banning the use of alcohol-based skin preparation solutions is likely to be unsuccessful. Internationally, advice is conflicting. In the UK in 2008 guidelines regarding the prevention of surgical wound infection included recommendations to continue to use alcoholic skin preparation solutions. ${ }^{8}$ The 2005 fire code published by the US National Fire Protection Association suggested that flammable surgical preparation fluids were never to be used in the presence of ignition sources. ${ }^{16}$ This led to controversy among surgeons and the American Society for Healthcare Engineering and it was amended within a few months to allow the use of alcohol-based solutions, provided an identified time-out is in place to ensure the skin preparation is dry. ${ }^{17}$

An alternative recommendation might be to include fire risk assessment in the pre-surgical World Health Organization checklist and to include fire awareness in the surgical curriculum, with the understanding that these methods will take some time to incorporate into medical practice.

\section{Conclusions}

Fire safety awareness has fallen since the decline in use of flammable anaesthetics. ${ }^{7}$ However, surgical fires are avoidable adverse incidents that continue to occur in modern hospitals. Assessment of the fire hazard when using spiritbased skin preparation fluid should be carried out at each use and the manufacturer's instructions followed to preserve patient safety. Continued work into the effectiveness of aqueous skin preparation fluids may eventually obviate the need for spirit-based solutions but until then it is essential to be aware of the potential for serious injury when these are used.

\section{References}

1. Retzlaff K. Fighting fire with preparation. AORN Connections. October 2009.

2. Briscoe CE, Hill DW, Payne JP. Inflammable antiseptics and theatre fires. $\mathrm{Br} \mathrm{J}$ Surg 1976; 63: 981-983.

3. A clinician's guide to surgical fires. How they occur, how to prevent them, how to put them out. Health Devices 2003; 32: 5-24.

4. Batra S, Gupta R. Alcohol based surgical prep solution and the risk of fire in the operating room: a case report. Patient Saf Surg 2008; 26: 10.

5. Prasad R, Quezado Z, St Andre A, O'Grady NP. Fires in the operating room and intensive care unit: awareness is the key to prevention. Anesth Analg 2006; 102: 172-174.

6. Report a Patient Safety Incident. National Patient Safety Agency. http://www.nrls.npsa.nhs.uk/report-a-patient-safety-incident/ (cited October 2011).

7. Yardley IE, Donaldson LJ. Surgical fires, a clear and present danger. Surgeon 2010; 8: 87-92.

8. National Institute for Health and Clinical Excellence. Surgical Site Infection. London: NICE; 2008.

9. Medicines and Healthcare products Regulatory Agency. SN 2000(17) - Use of Spirit-Based Solutions During Surgical Procedures Requiring the Use of Electrosurgical Equipment. London: MHRA; 2000.

10. ECRI Institute. New clinical guide to surgical fire prevention. Health Devices 2009; 38: 319.

11. Center for Medicaid. Use of Alcohol-based Skin Preparations in Anesthetizing Locations. Baltimore, MA: CMS; 2007

12. ChloraPrep ${ }^{\circledR}$ with Tint $2 \%$ w/v / $70 \%$ v/v Cutaneous Solution: Chlorhexidine Gluconate / Isopropyl Alcohol. Reigate: Enturia Ltd; 2009.

13. SPC: Betadine Alcoholic Solution. Electronic Medicines Compendium. http://www.medicines.org.uk/EMC/medicine/1950/SPC/ (cited October 2011).

14. Warnings. ChloraPrep. http://www.chloraprep.co.uk/warnings.html (cited October 2011).

15. SPS: ChloraPrep. Electronic Medicines Compendium. http://www.medicines.org.uk/emc/medicine/22302/SPC/ (cited October 2011).

16. National Fire Protection Association. NFPA 99: Standard for Health Care Facilities. Quincy, MA: NFPA; 2005.

17. National Fire Protection Association. NFPA 99: Standard for Health Care Facilities. Tentative Interim Amendment 05-02. Quincy, MA: NFPA; 2005

\section{Review articles}

The Annals publishes reviews that meet the following criteria:

- The review deals with a clinically relevant subject within the practice of any surgical specialty.

- The review contains a brief introduction, a methods section that describes the search strategy used and a clear analysis of all relevant publications.

- Clear conclusions are reached.

- A structured abstract with similar sections is required.

If you are considering submission of a review, please read the relevant section in the instructions to authors (http://www.rcseng.ac.uk/publications/submissions/authorinstructions.html) and if you have any doubt about the suitability of the topic, communicate with the Associate Editor (annals@rcseng.ac.uk). 